\title{
Issues at the Rural-Urban Fringe: The Land Use Debate--Situational Background ${ }^{1}$
}

Rodney L. Clouser²

This fact sheet is one in a series that addresses issues associated with land use at the rural-urban fringe. This fact sheet is designed to explain the background related to land use issues at the rural-urban fringe, conflicts that arise due to growth and use of land, and various methods used throughout the United States to slow the conversion of agricultural land to nonagricultural uses.

\section{Farmland Use Trends}

Throughout history, agriculture has been one of the biggest users of the U.S. land base. The total U.S. land base is approximately 2.3 billion acres. Many people are surprised that a general breakdown of use indicates that approximately 97 percent of those acres are classified as rural and used for range, cropland, pasture, farmsteads, roads, forests, and other miscellaneous uses. That means that only 3 percent of the U.S. land base is used for residential, commercial, utility, mixed, transitional, and other urban uses.

Translating the nation's 2.3 billion acres of rural land into various uses in 1997 demonstrates that about 28 percent (642 million acres) is forests, followed by 26 percent (586 million acres) for miscellaneous/special uses, 26 percent (580 million acres) for pasture and rangeland, and 20 percent (455 million acres) for cropland. Miscellaneous land use includes deserts and wetlands, and special land use includes parks, wildlife areas, rural roads, and defense areas. Florida's land use patterns differ from U.S. patterns, with forest use accounting for 42 percent (14.6 million acres), 31 percent in miscellaneous/special uses (10.9 million acres), pasture and rangeland 16 percent (5.5 million acres), and almost 11 percent in cropland (3.7 million acres).

A useful source of information for U.S. and Florida land use data is the Census of Agriculture. According to the 2002 Census, the farmland base in the United States declined between 1974 and 2002 from slightly more than 1 billion acres to about 938.3 million acres. This represents a national decline of approximately 78.7 million acres of farmland (7.8 percent) over a 28 -year period. The average conversion of farmland was 2.8 million acres per year between 1974 and 2002.

Florida land use data from the 2002 Census exhibit similar trends, but the rate of conversion is occurring at a faster pace. Between 1974 and 2002,

1. This is EDIS document FE551, a publication of the Department of Food and Resource Economics, Florida Cooperative Extension Service, Institute of Food and Agricultural Sciences, University of Florida, Gainesville, FL. This document is one of a series entitled "Issues at the Rural Urban Fringe". Published May 2005. Please visit the EDIS website at http://edis.ifas.ufl.edu.

2. Rodney L. Clouser, Professor and Public Policy Specialist, Department of Food and Resource Economics, Florida Cooperative Extension Service, Institute of Food and Agricultural Sciences, University of Florida, Gainesville, FL. 
the farmland base in Florida declined from 13.2 million acres to 10.4 million acres. This represents a net decline of 2.8 million acres of farmland (21.1 percent) over the same 28 -year period. The conversion of farmland has averaged 100,000 acres per year between 1974 and 2002. An interesting aspect of both the U.S. and Florida data is that the rate of farmland conversion has slowed considerably over the last decade. Between 1992 and 2002, the conversion of farmland has been 1 percent for the United States and 3.8 percent for Florida. To put this into perspective, in Florida, the rate of farmland conversion over the last 10 years has been about 40,000 acres per year compared to 100,000 acres per year over the 28-year time period.

Trends in farmland conversion have been documented and debated for many years. Some groups perceive the decline as a significant problem. Other groups claim alarmist tactics are being used to create a controversy that is nonexistent. Why the big difference in the severity of the issue of farmland conversion? Over a period of the last 30 to 50 years, there have been significant times when crop surpluses have existed, farm commodity prices have been low, and world food production has been increasing substantially. While the United States is a major agricultural exporter worldwide, U.S. programs have been developed to encourage farm producers to shift marginal lands from intensive to less intensive forms of production. This has led some to conclude that too much U.S. land remains in agriculture. On the other hand, people who have been involved in agriculture for generations have left the profession, leading some to argue that depending on foreign food production is a dangerous precedent, citing problems created by dependency on foreign oil and food, especially in light of the 9/11 attack on the United States, and foreign safety and health standards that do not meet U.S. expectations. This has caused concerns regarding agriculture remaining a viable industry in local economies and the desire for open spaces in and around high density population centers. Taking all these factors into consideration, it becomes easier to understand why disagreements on the significance of farmland conversion are so varied.

These concerns will be evaluated in the remainder of this fact sheet. Different viewpoints on the amount of agricultural land base and the significance of its decline must be explored from several perspectives, including individual, organizational, governmental, and societal. In a generic perspective, the issue can be divided into two broad categories: food production and nonfood production.

\section{Food Production Concerns}

Experts differ on the necessity of a stable land base for food production. Individuals less concerned with stability of the U.S. farmland production base note that the conversion of land (2.8 million acres between 1974 and 2002) represents an annual average rate of only about three-tenths of one percent in any given year. They also note that not all land removed from agriculture is actually used in food production, so the percentage decline in any given year is even smaller. Productivity and technological gains in U.S. food production, as well as food supply being a global issue, are also mentioned as reasons that the farmland base decline is not a critical concern. Between 1990 and 1999, farm output, even with a declining land base, has increased 20 percent. Likewise, the United States still exports a large part of food produced (in 2002, it was estimated that almost 22 percent of all U.S. production, by volume, was exported to other countries). All these factors could lead to the conclusion that, despite the conversion of farmland, the problem is insignificant.

Those most concerned with the conversion of farmland frequently acknowledge that while the change is small in any given year, when considered over a longer period of time, it is still substantial. These individuals and groups also express concern over the distribution of farmland conversion. For example, small amounts of land lost equally across the country and equally across commodities might not be a huge concern, but a large concentrated conversion in any one section of the country or in a specialty crop (e.g., winter vegetables) would be. The percentage conversion of land might be small, but the production loss in volume could be large.

People, organizations, and governments all seem to agree on a set of issues related to the farmland debate. Dependency on foreign suppliers of food 
products is a concern from a supply perspective, a food safety perspective, and a national security perspective. However, some would argue that any worldwide supply interruption could be offset by capacity available in the United States. Food safety has been a long-time concern, as illustrated by hoof-and-mouth diseases, and more recently mad-cow disease. However, changing production input use and regulations worldwide would at best be an extremely expensive challenge. Finally, repeated concerns about terrorism attacks on the United States through the food supply system have increased since 2001. Many individuals see the United States as very vulnerable, especially from imported food products. At the same time, others would argue that the United States is at risk for the introduction of biological agents into the local agricultural food production process, so the issue is much larger than just imported food products.

Other concerns are often raised regarding future food production and include issues such as restricted use of pesticides, increased competition for water resources, declining funding for research advancing farm production technology, other environmental concerns, and moral obligations related to world hunger. All these concerns may need to be included as part of the discussion concerning national, regional, state, and local farmland concerns.

\section{Agriculture and the Local Economy}

Granted, some sections of the United States produce a significant amount of specialty crops but, in general, food supply issues have a national and global perspective. According to the United States Department of Agriculture (USDA), there are only 440 counties in the United States that are classified as farming dependent. A farming-dependent county is defined as "either 15 percent or more of average annual labor and proprietors' earnings being derived from farming during 1998 to 2000, or 15 percent or more of employed residents working in farm occupations in 2000." In Florida, only Lafayette, Gilchrist, Hardee, Glades and Hendry Counties are identified as being farming dependent. A classification of Florida counties by type using USDA definitions is illustrated in the map in Figure 1. Even though few counties in the United States or
Florida are classified as farming dependent, this does not imply that agriculture is not important in local economies.
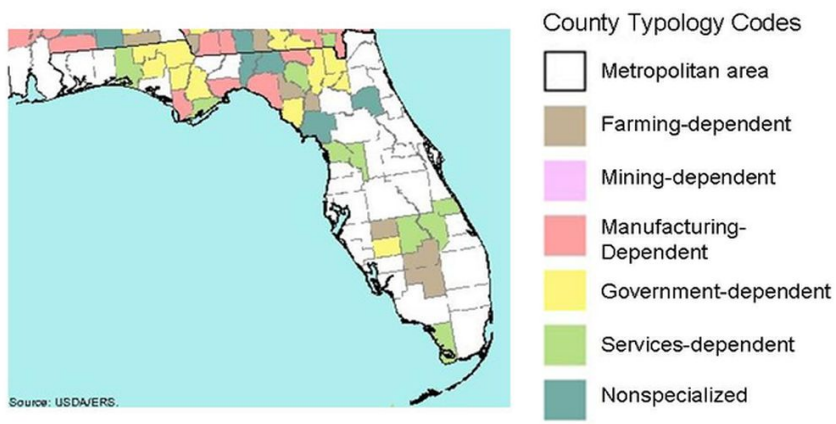

Figure 1. Classification of Florida counties by type using USDA definitions.

When agriculture is identified as an important industry in the local economy, there may be more urgency to consider the farmland base as critical in a local community or county. Collectively, there may be a certain level of agriculture producers or a critical mass of farmland necessary for businesses serving the industry, directly or indirectly, to survive. For example, fertilizer and chemical dealers need a certain mass of farmland close by to maintain business. Otherwise, the farm producer must get these inputs from other areas, thereby increasing the cost of the input. Once a critical mass of farmland disappears, the impact on industries serving the farm can decline rapidly. Impacts at the farm, business, or community levels are all unfavorable.

\section{Environmental and Other Considerations}

Many people see agricultural land as a picturesque, peaceful surrounding, especially in densely-populated urban and suburban environments. They generally think of benefits from agricultural land as open space, good air quality, scenic beauty, wildlife habitats, and water recharge. Agricultural land can have all these qualities, but often forgotten are other issues associated with agricultural land such as noise, dust, odors, etc. Those inclined to be concerned about the conversion of agricultural land might argue that favorable characteristics of agricultural land are undervalued by the land market, therefore resulting in too little land allocated to 
agricultural use. Farmland owners, on the other hand, tend to make the case that, if these characteristics have value, then society needs to pay for them.

\section{Summary}

What we know factually about agricultural lands is that base acreage is decreasing while the volume of production is increasing. Whether the decline in base acreage is a concern is not easily answered because it is dependent, not only on facts, but also on the values of individuals and governments. The ultimate resolution to this issue can be expected to extend over time and will be made both from facts and from societal values reflected through elected and appointed public decision makers. The issues identified in this fact sheet will be part of the public decision-making process.

\section{References}

Gordon, John, Rodney L. Clouser and David Mulkey. 1987. Maintaining Land for Agriculture: A Situation Statement. Food and Resource Economics Report FRE-26. Department of Food and Resource Economics, University of Florida, Gainesville, FL.

United States Department of Agriculture.2004. Briefing Room. United States Department of Agriculture, Economic Research Service, Washington, D.C. USDA website http://www.ers.usda.gov/briefing/rurality/Typology.

United States Department of Agriculture. 2005. Briefing Room. United States Department of Agriculture, Economic Research Service, Washington, D.C. USDA website http://www.ers.usda.gov/landuse/ majorlandusechapter/htm.

United States Department of Agriculture. 2003. Estimating Export Share of U.S. Agricultural Production. United States Department of Agriculture, Economic Research Service (Amber Waves), Washington, D.C. USDA website http://www.ers.usda.gov/AmberWaves/November03/ Indicators/ behinddata/htm.

United States Department of Agriculture. 2005. 2002 Census of Agriculture, Table 1. Historical
Highlights: 2002 and Earlier Census Years. United States Department of Agriculture, National Agricultural Statistics Service. NASS website http://www.nass.usda.gov/census. 